\title{
Poisson Regression Analysis with Tourism Data: Analysis of The Effects of Foreign Visitors' Local Tradership and Shopping Perceptions on The Frequency of Visit ${ }^{*}$ (Research Article)
}

\author{
Turizm Verileri ile Poisson Regresyon Analizi: Yabanci Ziyaretçilerin Yerel \\ Esnaf ve Alişveriş Algilarinin Ziyaret Sikliği Üzerine Etkilerinin Analizi
}

Doi: 10.29023/alanyaakademik.889572

\section{Hilmi KARAALİOĞLU}

PhD Student, Akdeniz University Institute of Social Sciences, Department of Econometrics, hilmi.karaalioglu@alanya.edu.tr

Orcid Id: 0000-0002-1620-5460

\section{Adil KORKMAZ}

Prof. Dr., Akdeniz University Faculty of Economics and Administrative Sciences, Department of Econometrics,

adilkorkmaz@akdeniz.edu.tr

Orcid Id 0000-0002-2432-518X

How to cite this article: Karaalioğlu, H. \& Korkmaz, A. (2021). "Poisson Regression Analysis with Tourism Data: Analysis of The Effects of Foreign Visitors' Local Tradership and Shopping Perceptions on The Frequency of Visit” Alanya Academic Review, Vol:5, No:3, pp.1443-1456.

Keywords:

Poisson regression, Alanya Tourism, Count variable, Count Data, Overdispersion Tourist Loyalty

Received: 02.03.2021 Accepted: 10.08 .2021

\begin{abstract}
Increasing the frequency of visits by foreign visitors is an important phenomenon in today's world, where the contribution of tourism, which is accepted as a chimneyfree industry, to the economies of developing countries is increasing. This phenomenon can be possible if foreign tourists have positive holiday experiences, develop positive perceptions and attitudes about Alanya holiday, and as a result, tourist loyalty is formed. For this purpose, a survey was conducted on foreign tourists who have finished their holiday in Alanya and are in the process of airport transfer, and the variables that are predicted to be effective on their revisit intentions are measured. In this study, in order to reveal the relations between the frequency of visits of foreign tourists and the attitudes of these individuals towards the perceptions of local tradesmen, factors were determined by factor analysis first, and then the mathematical relationship between these factors and the dependent variable of visit frequency, which is the counting variable, was analyzed in the Poisson regression model. As a result of the analysis, it has been seen that the factor of "the attitude of the tourist towards positive tradesman behavior and good
\end{abstract}

\footnotetext{
* Ethical appropriateness of the implementation of this study was determined by taking "Ethics Committee Approval" in accordance with the decision of Akdeniz University, Social and Human Sciences Scientific Research and Publication Ethics Board dated 29/01/2020 and numbered 07.

${ }^{\dagger}$ This article produced from thesis which is being prepared Hilmi KARAALİĞLU and supervising Prof. Dr. Adil KORKMAZ within Akdeniz University Institute of Social Sciences Department of Econometrics.
} 
product quality" increases the frequency of tourist visits in Alanya destination. On the other hand, it has been determined that the factors "tourist's attitude towards the cooperation of tradesmen with brokers", "tourist's attitude towards negative shopping experience", "tourist's attitude towards hotel services" and "tourist's attitude towards product prices" have reducing effects on the frequency of visits.

\section{INTRODUCTION}

In today's world, tourism, as a sector, is increasing its importance for the national economies within the service sector. For developing countries such as Turkey, tourism becomes a very important sector in terms of earning foreign currency, especially during periods when the exchange rate risk is high. Tourism is an important source of foreign exchange for Turkey, with an income of approximately 35 billion dollars in 2020 and a share of $4.6 \%$ in national income (TÜRSAB, 2020). Sustainability of this resource is possible by making tourism-oriented promotions and marketing the products at the international level, as well as ensuring that the visitors who come to the country leave the country in a satisfied way. Especially from the point of view of businesses, the higher the satisfaction of the customers, the higher the customer's revisit intention (Kotler, 2005:90).

Satisfaction is the basis of the formation of the tourist's re-visit intention regarding a destination. This phenomenon is expressed in the literature in the form of creating loyalty. Yoo and Bai (2013) define loyalty as retaining existing customers and creating loyal customers. Loyalty is a source of motivation for a customer to come back to a business over and over and even recommend it to others, without the need for advertising. Loyalty is the continuity of an individual's existing relationship with a brand, product, or service (Cyr, et al., 2006:3). As can be seen from these concepts, loyalty refers to the continuity of the behavior of an individual to purchase a good or service. In addition, loyalty has the role of gaining new customers by recommending them to others as a result of satisfaction with the purchased goods or services.

Although customer loyalty has levels such as low loyalty and high loyalty, the factors affecting loyalty occur at different levels. These factors can be caused by the individual such as gender, age, nationality, income status, as well as environmental such as business image, perceived service quality, shopping experiences. The phenomenon that creates loyalty is basically customer satisfaction. A satisfied customer, on the other hand, will consume more, and since he has a positive opinion about businesses, he will transfer this thought to other individuals and will become insensitive to competing businesses (Baytekin, 2005: 44).

The measure of a loyal customers loyalty can be observed by the frequency of visits to the business to which they are loyal. In this context, loyalty in tourism can be demonstrated by observing how often a tourist visits a business or a destination. Loyalty is not only directly related to the satisfaction felt, but also directly related to the negativities to be experienced. In this respect, within the scope of the doctoral thesis carried out by Karaalioğlu (2021), as a measure of the loyalty of foreign tourists visiting Alanya, the number of times they visited the city in the last 10 years was measured through a questionnaire and the factors affecting customer loyalty were revealed.

In statistics and econometrics, the number of repetitions and occurrences of an event in a certain period is expressed as count data. Basically, count data is non-negative data that takes integer 
values and appears as count data rather than ranking. Examples of count data include the number of times an insurance company's policies are exposed to risk in a year, or the number of times a foreign tourist visiting a city has visited that city in the last 10 years. Count data is frequently used in many fields such as actuarial, economics, statistics, and econometrics.

Count data models are specific regression types used when the dependent variable is discrete and a specific count data. Discrete and limited dependent variable models have been very popular in econometrics and have found a rich application area in microeconomics (Cameron and Trivedi, 2013:3). In order to understand the counting data better, to create meaningful models with these data and to obtain consistent estimates, some models and analyzes different from classical linear regression models are required. Because if classical linear regression techniques are applied to these data, the results may be inconsistent and contradictory.

Poisson regression model is one of the basic methods frequently used in the analysis of count data. The conditional probability of count data in the model is determined by the Poisson distribution. The conditional mean and variance of this distribution are equal. So, these two values of the dependent variable are expected to be equal. If the conditional mean and conditional variance are not equal, the problem of overdispersion will arise (NCSS, 2020). Overdispersion is when the observed variance is greater than the variance expected from the regression. (Field, 2009:276). In practice, when trying to estimate parameters using Poisson regression analysis, the problem of overdispersion is usually encountered. In order to overcome this problem, the variance and covariance matrices of the maximum likelihood estimators should be calculated, and the quasi maximum likelihood estimators should be obtained, or the Negative Binomial Model should be used instead of the Poisson regression model that accepts overdispersion (Mert, 2016:241).

In this study, with the help of the survey data obtained within the scope of the doctoral dissertation conducted by Karaalioğlu (2021), the number of times foreign tourists visited Alanya was observed and the assumptions of the Poisson regression analysis were examined in this counting data; Significant inferences were made with the relevant dependent variable.

\section{POISSON REGRESSION ANALYSIS}

The Poisson regression model is used in cases where the dependent variable is expressed as count and ratio variable, takes non-negative integer values, but is not categorical. In other words, the dependent variable must be a discrete random variable. This model is derived from the Poisson distribution by allowing the density parameter $\mu$ to depend on common variables (regressors). This distribution is a distribution that gives the probability of an event occurring in a certain period of time. Therefore, in the model, the dependent variable $Y$ can be a count variable or a ratio in the form of $Y / t$. Here $t$ can represent a certain time, a set, or another group. Therefore, the model is quite similar to Logistic regression, except that the dependent variable $Y$ is the counting variable.

A standard application of Poisson regression is cross-section data. Typical cross-sectional data for applied work consists of $n$ independent observations, of which the i-th observation is $\left(y_{i}, x_{i}\right)$. Scalar dependent variable $y_{i}$ is the frequency or number of occurrences of the event involved; The $x_{i}$ independent variable is a linear independent vector thought to determine the dependent variable. For the regression model that fits this distribution, the $k$ dimensional $x_{i}$ vector is in the form $\boldsymbol{x}_{\boldsymbol{i}}^{\prime}=\left[x_{1 i}, \cdots, x_{k i}\right]$. As a result, Poisson regression analysis explains the 
mathematical relationship between dependent count variable $y_{i}$ and independent $x_{i}$ explanatory variables. There are no constraints for explanatory $x_{i}$ dependent variables in these models (Cambridge University Press, 2021).

The fact that the dependent variable is count data provides a motivation for choosing the Poisson distribution. Expressing the mean exponentially as in Eq. (2.1) ensures that the parameter $\mu_{i}$ is nonnegative. The method used in the estimation of the model is the Maximum Likelihood method. In order to obtain effective estimators with this method, the observed variance should not be greater than the expected variance, that is, there should be no overdispersion problem in the model. If this requirement is neglected, estimators may encounter narrower confidence intervals than they should be for test statistics. In this case, there will be an excessive confidence in the effect of the estimators on the result and the probability of type 1 error will increase. Therefore, if overdispersion is observed in the model, either the overdispersion should be eliminated or the Binomial distribution, which can give more effective estimates, should be preferred (NCSS, 2020).

In Poisson regression analysis, generally in integer models, too many observations that take zero value in the structure of the dependent variable can cause some distortions in the model because it will shrink the average of the variable too much. In this case, there may be changes in the methods to be applied. In this case, the model's compliance with the Hurdle regression model can be tested. In hurdle regression models, under the assumption that the distributions of the dependent variable y are $y=0$ and $y>0$ are different, errors that may occur when the dependent variable takes the value of zero are modeled. (Mert, 2016:256).

As it is known, classical linear regression models are used when the dependent variable is a continuous variable. However, there are different regression methods recommended depending on whether the dependent variable is restricted or not, or in cases where observations cannot be made for some levels of the dependent variable. If it is not possible to observe for some values of the dependent variable or if the values of the dependent variable are not defined at certain intervals, models such as the Restricted Model, Tobit model, Generalized Tobit or Hidden variable models can be used because the dependent variable is censored or truncated.

When the dependent variable is categorical, different models are suggested for the number of categories and the type of scale in the categories. If the number of categories in the dependent variable is two and it is of nominal scale type, Logit or Probit models are used; Multinomial logit or Ordered logit models are recommended when the number of categories in the dependent variable is more than two. Again, the point to be considered here is the type of scale in the dependent variable. Because if the scale is in nominal type, Multinomial logit should be used, and if it is in an ordinal structure, Ordinal logit models should be used.

\subsection{Poisson Distribution and Regression Model}

The Poisson distribution models the dependent count variable $y$ with the formula (Field, 2009):

$$
P\left((Y=y \mid \mu)=\frac{e^{-\mu} \mu^{y}}{y !}\right.
$$

where $\mu$ is the mean of the distribution and $\mathrm{y}$ is the counting variable expressing the frequency or rate desired to occur $(\mu>0, y=0,1,2, \ldots)$. In log-linear versions of the model, the mean is shown as:

$$
\mu_{i}=\exp \left(\boldsymbol{x}_{\boldsymbol{i}}{ }^{\prime} \beta_{j}\right)
$$




$$
=\exp \left(x_{1 i} \beta_{1}\right) \exp \left(x_{2 i} \beta_{2}\right) \cdots \exp \left(x_{k i} \beta_{k}\right)
$$

As can be seen from Eq. (2.3), in Poisson regression, models are created with the assumption that $\mu$ parameter is determined by a series of $x_{i}$ variables. Hence, the $\mu$ parameter can be represented as an exponential mean function:

$$
\begin{aligned}
& E\left(y_{i} / x_{i}\right)=\mu_{i}=e^{x_{i} \beta_{j}} \\
& \mu_{i}=\exp \left(\beta_{1} x_{1}+\beta_{2} x_{2}+\cdots+\beta_{k} x_{k}\right) \\
& \mu_{i}=\mu\left(x_{i}^{\prime} \beta\right)
\end{aligned}
$$

Here, the regression coefficients $\beta_{1}, \beta_{2}, \cdots, \beta_{k}$ are unknown parameters to be estimated using the data set. If the natural logarithm of Eq. (2.2) is taken, a linear shape of the conditional mean according to the $x_{i}$ variables is obtained. Although the dependent variable is a discrete random variable, Poisson regression models are nonlinear models due to their functional form as can be seen in Eq. (2.4).

Regression coefficients are estimated using the maximum likelihood method. The logarithm of the likelihood function is (Field, 2009):

$$
\ln [L(y, \beta)]=\sum_{i=1}^{n} y_{i} \ln \left[\mu\left(\boldsymbol{x}_{\boldsymbol{i}}^{\prime} \beta\right)\right]-\sum_{i=1}^{n} \mu\left(\boldsymbol{x}_{\boldsymbol{i}}^{\prime} \beta\right)-\sum_{i=1}^{n} \ln \left(y_{i} !\right)
$$

With the solution obtained by taking the differential of Eq. (2.7) with respect to the $\beta$ parameter, the Poisson maximum likelihood estimators $\widehat{\boldsymbol{\beta}}_{\boldsymbol{i}}$ are calculated using the following equation:

$$
\sum_{i=1}^{n}\left(y_{i}-\exp \left(\boldsymbol{x}_{\boldsymbol{i}}^{\prime} \beta\right)\right) x_{i}=0
$$

Likelihood equations are created by taking derivatives according to each regression coefficient and equating the result to zero. Doing so leads to the emergence of a set of nonlinear equations that accept no closed form solution. For this reason, iterative algorithms such as NewtonRaphson are used to find regression coefficients that maximize likelihood. It is seen that Fisher iteration method is used frequently in the literature.

One of the consequences of not finding an analytical solution for $\widehat{\boldsymbol{\beta}}$ is the difficulty of obtaining exact distribution results for $\widehat{\boldsymbol{\beta}}$ estimators. There are several ways to infer for $\widehat{\boldsymbol{\beta}}$. First, consider $\widehat{\boldsymbol{\beta}}$ as the estimator that maximizes Eq. (2.7) and maximum likelihood theory should be applied. Second, the estimator $\widehat{\boldsymbol{\beta}}$ must be considered as defined by Eq. (2.8). These equations have a similar interpretation to Ordinary Least Squares (OLS) estimators. Therefore, the unweighted residuals $\left(y_{i}-\mu_{i}\right)$ are orthogonal to the estimators. Therefore, as for OLS, it is possible to perform the inference only under assumptions about the mean and possibly variance. This is a generalized linear models approach. Third, since Eq. (2.6) implies the equation $E\left(y_{i}-\right.$ $\left.\exp \left(\boldsymbol{x}_{\boldsymbol{i}}^{\prime} \beta\right)\right) x_{i}=0$, an estimator can be defined that is the solution of the moment condition in the sample. This estimator is also the solution of Eq. (2.8). This approach is the moment-based models approach (Cameron and Trivedi, 2013:23). 
Datasets to be analyzed by Poisson regression must contain at least one dependent variable and one or more independent variables. For each categorical variable, the analysis program creates a set of binary ( 0 and 1$)$ variables expressing the same information. If any of the independent variables used have missing values, that row is skipped. If only the value of the dependent variable is missing, this row is not used during the prediction process, but its predicted value is generated (NCSS, 2020).

\subsubsection{Likelihood-Based Poisson Regression Model}

Suppose that the scalar random variable $y_{i}$ given by the regression vectors $x_{i}$ and the parameter vector $\theta$ are distributed by the density $f\left(\left(y_{i} \mid x_{i}, \theta\right)\right)$. According to the likelihood principle, the value that maximizes the probability of observing $y_{i}$ values is chosen as the estimator of $\theta$ parameters. This probability, which is a function of conditional parameters to the data, is called the likelihood function and is represented as (Cameron and Trivedi, 2013:25):

$$
\mathrm{L}(\theta)=\prod_{i=1}^{n} f\left(\left(y_{i} \mid x_{i}, \theta\right)\right.
$$

This definition implicitly assumes section data but can easily accommodate time series data by expanding $x_{i}$ to include delayed dependent and independent variables. Maximizing the likelihood function is equivalent to maximizing the log-likelihood function. Then the following equation can be written:

$$
\mathcal{L}(\theta)=\ln [\mathrm{L}(\theta)]=\sum_{i=1}^{n} \ln f\left(\left(y_{i} \mid x_{i}, \theta\right)\right.
$$

The performance of the Poisson regression model is measured by two Chi-square tests. The first of these tests is the Pearson Chi-square statistic (Chi-square fit test), which reveals which theoretical distribution a data set is suitable for:

$$
P_{p}=\sum_{i=1}^{n} \frac{\left(y_{i}-\hat{\mu}_{i}\right)^{2}}{\hat{\mu}_{i}}
$$

Another Chi-square test that measures model performance is the deviation or $G$ statistic:

$$
D_{p}=\sum_{i=1}^{n}\left\{y_{i} \ln \left(\frac{y_{i}}{\hat{\mu}_{i}}\right)-\left(y_{i}-\hat{\mu}_{i}\right)\right\}
$$

Both tests expressed with Eq. (2.11) and Eq. (2.12) have chi-square distribution with $n-k$ degrees of freedom. If one of these tests is rejected there is a significant lack of compliance. However, if the tests are not rejected, lack of compliance is not mentioned. Since Pearson statistics has a chi-square distribution in the analysis of categorical variables, it is necessary to use the frequency variable to use this test for goodness of fit. This test is also frequently used to detect the presence of overdispersion in the series (Cameron and Trivedi, 2009:26).

\subsubsection{Interpretation of Coefficients}

Interpretation of $\widehat{\boldsymbol{\beta}}_{\boldsymbol{i}}$ coefficients obtained by Poisson regression model differs from linear regression. This difference is due to the fact that the expected value in the Poisson regression 1448 
model is the exponential conditional mean in the form $E(y \mid x)=\exp \left(\boldsymbol{x}_{\boldsymbol{i}}^{\prime} \beta\right)$. If taken the partial derivative of this conditional mean with respect to $x_{i}$, the following equation is obtained:

$$
\frac{\partial E(y \mid x)}{\partial x_{i}}=\beta_{i} \exp \left(\boldsymbol{x}_{\boldsymbol{i}}^{\prime} \beta\right)
$$

Since Poisson regression models have an exponential distribution as stated in Eq. (2.1) and Eq.(2.2), analyzes are made by taking the natural logarithm of the dependent variable. Therefore, this situation should be considered when interpreting the coefficients. While making estimates, technical attention should be paid to the significance of the coefficients and the signs of the coefficients. For example, in an expression such as $\beta_{k} x_{m}$ in a Poisson regression model, if the coefficient of the $x_{m}$ variable $\beta_{k}$ is statistically significant $(p<0,01)$; It is interpreted that a one-unit change in variable $x_{m}$ increases the natural logarithm of the dependent variable $y_{m}$ by $\beta_{k}$. (If the sign is negative, it is interpreted as decreasing by $\beta_{k}$.)

\subsection{Literature Review}

It is seen that the concept of loyalty was first examined in the literature for industrial products used in daily life such as toothpaste and detergent (Çatı and Koçoğlu, 2008:168). Later, Stank et al. (1999) examined the concept of loyalty for the fast food industry and revealed the positive effects of increasing service quality on loyalty. Sirohi et al. (1998) revealed that it is more important to create loyal customers than to acquire new customers. Kim (2008) revealed that with the increasing competition between tourism destinations, it is critical to maintain loyalty in order to create more competitive and preferable destinations.

For a destination, loyalty is important in terms of ensuring that the tourist's intention to revisit is positive and to have a positive attitude towards the tourism experience. Looking at the studies on revisit intention, Özdemir (2019) revealed with simple linear regression analysis that the variables of satisfaction, word of mouth, and value have a positive effect on revisit intention. Yurcu (2019) examined the revisit intentions of tourists visiting Kemer and Alanya destinations according to their demographic characteristics such as age, gender, income level and education, and used t-test and one-way analysis of variance (ANOVA) as analysis methods. Keskin et al. (2020) revealed that the dimensions of renewal, hedonism and meaningfulness of a positive memorable tourism experience have significant effects on satisfaction and therefore on revisit intention. In their analysis, they used factor analysis and correlation analysis.

In tourism, it is important to examine the factors that can affect loyalty positively and make a positive contribution in this direction and to reveal the negative situations, if any ( $\mathrm{Su}$, et al., 2011). Considering the relationship between the holiday experiences of tourists and the attitudes of local tradesmen towards them, it is seen that the number of studies on this subject is few in the literature. Üngüren et al., (2015) used non-parametric techniques (chi-square) to analyze the effect of hanutism and hanutists (a type of brokerage), which is expressed as a type of tourist harassment, on tourists and revealed the reasons why tourists avoid local shopkeepers in their shopping. Sar1 and Bayraktar (2018) examined the tourist perceptions of shopkeepers in Kemer district using central tendency measures (averages and cross tables); It has been revealed that tradesmen are more interested in tourism and foreign tourists and they see the tourist as a guest. Güçlü and Yılmaz (2020) made comparisons by using t-tests to determine the perceptions of foreign tourists about Alanya destination before and after their holiday and 
they revealed that tourists' image perceptions consist of services, transportation, beach, local people, nightlife, local tradesmen, and natural beauties.

When the literature is examined, it is seen that the effects of foreign tourists' attitudes towards their experiences with local tradesmen on their revisit intentions have not been examined, and no study has been conducted on this subject by using counting data and Poisson regression analysis. In this context, with the current data set and Poisson regression analysis, it has become necessary to examine the effects of foreign tourists' attitudes towards their experiences with local tradesmen on the frequency of visits to Alanya.

\subsection{Application, Dataset and Descriptive Statistics}

The data set used in this study is derived from the survey data obtained within the scope of the doctoral thesis titled "Analysis of the Perceptions of Foreign Tourists Staying in Alanya with Econometric Methods" preparing by Karaalioğlu (2021). The sample of the study was limited to the foreign tourists who came to Alanya for holiday in the period of 2019 - 2020 May October, and observations were made on the tourists in the airport transfer process at the end of the holiday with the convenience sampling method. 564 participants from 18 different countries were included in the study. These participants consisted of 324 (57.4\%) female and $240(42.6 \%)$ male individuals. In this context, the participants were asked questions measuring the attitudes of local tradesmen on foreign visitors along with questions measuring demographic information.

In the study, the frequency of the participants' visits to Alanya over a period of 10 years was measured and the effects of the attitudes of local tradesmen on tourists on this variable were tried to be determined. As the number of visits data is a count data, the Poisson regression analysis method was preferred. In this context, the assumptions of the model were examined and the factors affecting the number of visits were tried to be determined.

Factor analysis is an effective method for both reducing the number of variables and avoiding multiple linear connection problems in the regression model we will make. As in many studies in social science, varimax rotation was preferred in the determination of factors in our study. The factor loads obtained by varimax rotation were compared with the loads obtained by Direct Oblimin and Promax methods, which are oblique rotation methods, within the scope of The Confirmer Factor analysis. As a result of this comparison, the stability of the factors was determined because very close results were obtained. Cronbach's Alpha reliability coefficients of the factors obtained by factor analysis were found to be higher than 0.60 on average. In this respect, it can be said that the scales measuring the perceptions of local tradesmen on foreign visitors are reliable. The frequency of foreign visitors visiting Alanya for a period of 10 years has been examined, and this value is accepted as the dependent variable; The effect of five factors determined by factor analysis on the number of visits was analyzed.

Table 2.1 KMO and Bartlett Test of Sphericity for factor analysis

\begin{tabular}{|l|r|r|}
\hline \multicolumn{2}{|c|}{ KMO and Bartlett's Test } \\
\hline Kaiser-Meyer-Olkin Measure of Sampling Adequacy. &, 695 \\
Bartlett's Test of Sphericity & Approx. Chi-Square & 976,113 \\
& df & 78 \\
\cline { 2 - 3 } & Sig. &, 000 \\
\hline
\end{tabular}


As can be seen from Table 2.1, KMO is calculated as 0.695 . The fact that this value is greater than 0.60 indicates that the data set is suitable for factor analysis. In addition, since the $\mathrm{p}$ value is $\mathrm{p}=0.000$ according to the Bartlett test, the alternative hypothesis claiming that the correlation matrix is different from the unit matrix will be accepted and it will be concluded that the data set is suitable for factor analysis. The factors and factor components obtained in this way are given in Table 2.2.

Table 2.2 factors and factor components obtained as a result of factor analysis

KMO = 0.695

Chi-square for Bartlett test $=976,113, P$ - value $=0.00$

Total variance explained $=\% 59.78$

Cronbach Alpha=0.724

Factor 1 (F1): SELLER BEHAVIOR AND PRODUCT QUALITY: The tourist's attitude towards seller behavior and product quality

(Total variance explained: \% 16.299, Cronbach Alpha=0.609)

Q2: The approach of local tradesmen towards me has positively influenced my decision to visit Alanya again. $(0.730)$

Q10: My local craftsmen and shopping experience has a positive impact on my intention to visit Alanya again. (0.619)

Q7: I'm glad the tradesmen welcome us. (0.596)

Q9: I will come back to Alanya for the holidays at the earliest opportunity. (0.557)

Q4: I am pleased with the quality of Turkish products in general. (0.464)

Factor 2 (F2): SELLER-COMMISSIONER (HANUTIST) COOPERATION: The attitude of the tourist when the tradesman cooperates with the brokers

(Total variance explained: \% 13.015 Cronbach Alpha=0.564)

Q5: I'm afraid to shop at local shops. (0.790)

Q6: I prefer shopping malls. (0.765)

Q13: I have observed significant differences between the price of the label in my purchases and the discounted prices I have obtained from the bargain. (0.561)

Factor 3 (F3): SHOPPING EXPERIENCE: Attitude of the tourist depending on the shopping experience

(Total variance explained: \% 12.794 Cronbach Alpha=0.533)

Q14: Our guides have taken us to certain places to eat, drink or shop in bulk. (0.725)

Q3: After shopping, I was more confident with the vendors. (-0.677)

Q12: There were moments when I thought I'd cost a lot more than I should have a product in a shopping or service offered to me. (0.665)

Factor 4 (F4): HOTEL SERVICES: The attitude of the tourist towards hotel services

(Total variance explained: \%9.291)

Q8: I didn't feel the need to go out of the hotel for shopping because I could reach many amenities in the hotel and around the all-inclusive system. (0.888)

Factor 5 (F5): PRODUCT PRICING: The tourist's attitude towards product prices

(Total variance explained: \%8.381)

Q11: There were moments when I thought I'd cost a lot more than I should have a product in a shopping or service offered to me. (0.901)

The obtained data were analyzed with the SPSS program, and the compatibility of the dependent variable with the Poisson distribution was tested with the Kolmogorov-Smirnov test, and according to the test result, it was observed that the variable fits the Poisson distribution. However, the requirement that the variance and mean values of the Poisson distribution should be equal was examined on the variable, and the variance was calculated as 2.1514 and the mean 
as 2.2021 at the end of the test. Since these values are very close to each other, it has been observed that the necessity of being equal is provided.

There are two statistics to consider in the estimation of the Poisson model. One of them is the deviance goodness of fit and the other is Pearson's goodness of fit. These statistics show whether the model estimated by Poisson regression fits well with the available data set. Accordingly, the significance of goodness-of-fitness is seen in Table 2.3.

Table 2.3 Goodness of fit test results for the Poisson regression model (obtained by STATA)

\begin{tabular}{|ll|}
\hline estat gof & \\
\hline Deviance goodness - of - fit & $=568.7356$ \\
Prob $>$ chi2 (558) & $=0.3672$ \\
& $=489.3146$ \\
Pearson goodness - of - fit & $=0.9833$ \\
Prob $>$ chi2 (558) &
\end{tabular}

The goodness of fit test results of the model is also shown as in Table 2.3. In order to detect overdispersion in the model, the dispersion parameter is checked. This parameter is the ratio of the Pearson $\chi^{2}$ Goodness of Fit statistic or deviation value to the degrees of freedom. The fact that this value is very close to 1 indicates that there is no overdispersion problem in the model. As seen in Table 2.4, it can be said that there is no overdispersion problem since the dispersion parameter is 1.019 in the model.

Table 2.4 Goodness of fit test results for the Poisson regression model (obtained by SPSS)

Goodness of Fit ${ }^{\mathrm{a}}$

\begin{tabular}{|l|c|r|r|}
\hline & \multicolumn{1}{|c|}{ Value } & \multicolumn{1}{|c|}{ df } & Value/df \\
\hline Deviance & 568,736 & 558 & 1,019 \\
Scaled Deviance & 568,736 & 558 & \\
Pearson Chi-Square & 489,315 & 558 &, 877 \\
Scaled Pearson Chi- & 489,315 & 558 & \\
Square & $-950,689$ & & \\
Log Likelihood $^{\text {b }}$ & 1913,377 & & \\
Akaike's Information & & & \\
Criterion (AIC) & 1913,528 & & \\
Finite Sample Corrected & & & \\
AlC (AICC) & 1939,388 & & \\
Bayesian Information & & \\
Criterion (BIC) & 1945,388 & & \\
Consistent AIC (CAIC) & & \\
\hline
\end{tabular}

Dependent Variable: Ziyaret sayisi

Model: (Intercept), F1, F2, F3, F4, F5

a. Information criteria are in smaller-is-better form

b. The full log likelihood function is displayed and used in computing information criteria. 
As a result of the analysis, the parameter estimates of the model were obtained as follows:

Table 2.5 Parameter estimates of Poisson regression analysis

Parameter Estimates

\begin{tabular}{|c|c|c|c|c|c|c|c|c|c|c|}
\hline \multirow[b]{2}{*}{ Parameter } & \multirow[b]{2}{*}{$\mathrm{B}$} & \multirow[b]{2}{*}{ Std. Error } & \multicolumn{2}{|c|}{$95 \%$ Wald Confidence Interval } & \multicolumn{3}{|c|}{ Hypothesis Test } & \multirow[b]{2}{*}{$\operatorname{Exp}(B)$} & \multicolumn{2}{|c|}{$\begin{array}{l}95 \% \text { Wald Confidence Interval } \\
\text { for } \operatorname{Exp}(B)\end{array}$} \\
\hline & & & Lower & Upper & $\begin{array}{l}\text { Wald Chi- } \\
\text { Square }\end{array}$ & df & Sig. & & Lower & Upper \\
\hline (Intercept) & 1,384 & 1916 & 1,009 & 1,759 & 52,190 & 1 & .000 & 3,991 & 2,741 & 5,809 \\
\hline F1 &, 045 &, 0144 &, 016 &, 073 & 9,493 & 1 &, 002 & 1,046 & 1,016 & 1,076 \\
\hline $\mathrm{F} 2$ &,- 053 &, 0136 &,- 080 &,- 026 & 15,055 & 1 &, 000 &, 948 & ,923 & 974 \\
\hline F3 &,- 077 &, 0161 &,- 108 &,- 045 & 22,616 & 1 &, 000 & 926 &, 897 &, 956 \\
\hline $\mathrm{F} 4$ &,- 151 &, 0232 &,- 196 &,- 105 & 42,308 & 1 &, 000 & 860 &, 822 &, 900 \\
\hline $\begin{array}{l}\text { F5 } \\
\text { (Scale) }\end{array}$ & $\begin{array}{r}-, 095 \\
1^{\mathrm{a}}\end{array}$ &, 0320 &,- 158 &,- 033 & 8,898 & 1 &, 003 & ,909 & ,854 & ,968 \\
\hline
\end{tabular}

It is seen that all parameters are significant in the model. $\operatorname{Exp}(B)$ values are checked in the interpretation of the table. Different inferences are made depending on whether this value is equal to 1 or greater or less than 1 . For example, the effect of $F_{2}$, in other words, "Avoidance of local trades and commissioning referrals" variable on "frequency of visits" is negative. The interpretation of the value of 0.052 , which will be calculated by taking the difference of 0.948 value from 1 , will be that "one unit increase in $F_{2}$ decreases the number of visits by $5.2 \%$ ". Then, the results found can be listed as follows, under the assumption that other variables are constant (ceteris paribus):

- $\quad F_{2}$ : One-unit increase in the expression "Avoidance of local trades and commissioning referrals" reduces the frequency of foreign visitors visiting Alanya by $5.2 \%$.

- $F_{3}$ : One-unit increase in the expression "Negative perception from the shopping experience" decreases the frequency of foreign visitors visiting Alanya by $7.4 \%$.

- $\quad F_{4}$ : One-unit increase in the expression "The perception of not needing to shop outside the hotel due to the all-inclusive system" decreases the frequency of foreign visitors visiting Alanya by $14 \%$.

- $\quad F_{5}$ : One-unit increase in the expression "The opinion of expensiveness in shopping" decreases the frequency of foreign visitors visiting Alanya by $9.1 \%$.

- $\quad F_{1}$ : One-unit increase in the expression "Satisfaction with tradesmen" decreases the frequency of foreign visitors visiting Alanya by $4.6 \%$.

When interpreting the parameters as above, if we look at the value of $B$ rather than the $\operatorname{Exp}(B)$ value shown in Table 2.5, the interpretation should be made by considering the logarithm of the dependent variable. In this case, for example, it is interpreted as "The one-unit increase in the 'Avoidance of local trades and commissioning referrals' decreases the natural logarithm of the frequency of foreign visitors visiting Alanya by 0.053 units". However, in this case, the reverse logarithm operation should also be done. Thus, the same parameter comments listed above can be reached. 


\section{CONCLUSION}

Within the scope of the doctoral thesis being prepared by Karaalioğlu (2021), a survey was conducted on 564 foreign tourists among the foreign tourists who visited Alanya, and in this context, the relationship between the frequency of the participants' visits to Alanya and the perceptions of local tradesmen on foreign tourists were analyzed. The collected data were analyzed with the SPSS 22 and STATA 16 package programs.

Unlike the literature, the phenomenon of tourist loyalty in Alanya destination has been examined by associating it with the number of times tourists have visited this destination in the last 10 years. The number of visits in this period was considered as the frequency of visits and, in this respect, considering that the data at hand was a count data, it was analyzed with the Poisson regression model. It was seen that the data set fit well with the model, and then overdispersion, which is an important assumption of the model, was examined and it was revealed that the data set did not show overdispersion. After these examinations, the model parameters were estimated, and the estimation results were shown. As a result of the analysis, it has been seen that the factor of "the attitude of the tourist towards positive tradesman behavior and good product quality" increases the frequency of tourist visits in Alanya destination. On the other hand, it has been determined that the factors "tourist's attitude towards the cooperation of tradesmen with brokers", "tourist's attitude towards negative shopping experience", "tourist's attitude towards hotel services" and "tourist's attitude towards product prices" have reducing effects on the frequency of visits.

Since the frequency of visit data is a count variable, the suitability of this variable to the Poisson regression model was tested and then the model was applied. According to the results, there has been a significant decrease in the frequency of foreign visitors who have a negative perception after shopping in Alanya. In addition, it has been determined that the fact that foreign visitors have access to all facilities including shopping within the hotel in the all-inclusive system is a factor that reduces the frequency of visits. Reasons such as the inability of tourists to know or mis-recognize the country due to its all-inclusive system, leaving the country unaware of Turkey's natural, historical, and cultural assets can be shown as the negative aspects of the system.

In addition, positive satisfaction gained after shopping has been identified as a factor increasing the frequency of visits. Considering the effects on the dependent variable, the negative effect created by encountering a negative situation is stronger than the positive effect created by a positive situation.

As a result of the findings obtained, "A tourist brings a thousand tourists. Thanks to our shopkeepers who do their job properly. " The appropriateness of the campaign carried out with the statement is once again understood. In this context, in order to increase the frequency of visiting foreign visitors, it is necessary to reduce negative tradesmen behavior and improve the perceptions of tradesmen on foreign visitors. 


\section{REFERENCES}

BAYTEKIN, P., (2005), "Toplam Kalite Hedefinde Müşteri Memnuniyetinden Müşteri Sadakatine" Yeni Düşünceler Dergisi, Year 1, Number 1, 41-52.

CAMERON, A. C., \& TRIVEDI, P. K. (2013). Regression Analysis of Count Data Second Edition. Cambridge University Press, New York.

CAMERON, A. C., \& TRIVEDI, P. K., Cambridge University Press, "Regression Analysis of Count Data", http://assets.cambridge.org/97805216/32010/excerpt/9780521632010_excerpt.pdf, 02.01 .2021$.

CYR, D., (2006), "The Role of Social Presence in Establishing Loyalty in E-Service Environments", Interacting with Computers, Volume 19, Issue 1, January 2007, 43 56.

ÇATI, K. \& KOÇOĞLU, C. M. (2008). "Müşteri Sadakati ile Müşteri Tatmini Arasındaki İlişkiyi Belirlemeye Yönelik Bir Araştırma". Selcuk University Journal of Social Sciences Institute Issue: 19.

DENIZ, Ö. (2005). "Poisson Regresyon Analizi”, Istanbul Commerce University Journal of Science, Year:4 Number:7 Spring 2005/1: 59 - 72.

FIELD, A. (2009). Discovering Statistics Using SPSS Third Edition (and sex and drugs and rock 'n' roll). SAGE Publications Ltd, London, England.

GÜÇLÜ C, \& YILMAZ Y (2020). Tatil Öncesi ve Sonrası Destinasyon İmajı Karşılaştırması: Alanya Örneği. Journal of Travel and Hotel Management, 17(2), 173 - 185.

HINTZE, J.L., NCSS, "NCSS User's Guide III", https://inba.info/ncss3 574dc875b6d87fa90d8b5e0f.html, 07.09.2020.

KESKIN, E., SEZEN, N. \& DAĞ, T. (2020). Unutulmaz Turizm Deneyimi, Müşteri Memnuniyeti, Tekrar Ziyaret ve Tavsiye Etme Niyeti Arasındaki İlişkiler: Kapadokya Bölgesini Ziyaret Eden Turistlere Yönelik Araştırma. Journal of Recreation and Tourism Research, 7 (2), 239-264.

KIM, K. (2008), 'Analysis of Structural Equation Modelfor the Student Pleasure Travel Market: Motivation, Involvement, Satisfaction, and Destination Loyalty'. Journal of Travel \& Tourism Marketing, 24 (4), 297-313.

KOTLER, P. \& ARMSTRONG, G. (2005). “Principles of Marketing”. Pearson/Prentice-Hall Inc. New Jersey.

KÜÇÜKER, C., ÇOLAKOĞLU, Ü. \& YURCU, G. (2019). Rus Turistlerin Tekrar Ziyaret Etme Niyetlerinin Demografik Değişkenler Açısından İncelenmesi, Turkish Journal of Tourism Studies, 3(3): 646-659. 
MERT, M. (2016). SPSS STATA Yatay Kesit Veri Analizi Bilgisayar Uygulamalarl. Detay Yayıncılık, Ankara.

ÖZDEMIR, O. (2019). "Destinasyon İmajının Turistlerin Memnuniyetine ve Tekrar Ziyaret Etme Niyetine Etkisi: Mardin İli Üzerine Bir Araştırma”. Journal of Economics and Administrative Approaches, 1 (1), 65-77.

SARI, C. \& BAYRAKTAR, S. E., (2018), “Artisan attitudes towards tourism and tourist in Kemer district", International Geography Symposium on the 30th Anniversary of TUCAUM 3-6 Ekim 2018 /3-6 October 2018, Ankara, 167 - 189.

SIROHI, N., MCLAUGHLIN, E. W., \& WITTINK, D. R. (1998). A model of consumer perceptions and store loyalty intentions for a supermarket retailer. Journal of retailing, 74(2), 223-245.

STANK, T. P., GOLDSBY, T. J., \& VICKERY, S. K. (1999). Effect of service supplier performance on satisfaction and loyalty of store managers in the fast food industry. Journal of operations management, 17(4), 429-447.

SU, H.-J., CHENG, K-F. \& HUANG, H-H. (2011), 'Empirical Study of Destination Loyalty and Its Antecedent: The Perspective of Place Attachment', The Service Industries Journal, 31, (16), 2721-2739.

TÜRSAB, “Tourism Revenues”, https://www.tursab.org.tr/istatistikler-icerik/turizm-geliri, (date of access: 04.08.2020).

YOO, M. \& BAI, B. (2013), 'Customer Loyalty Marketing Research: A Comparative Approach Between Hospitality and Business Journals'. International Journal of Hospitality Management, 33, 166-177. 